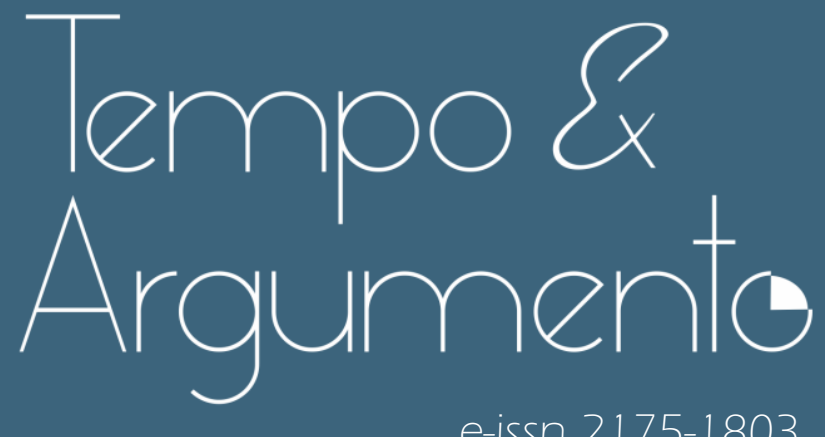

e-issn 2175-1803

Uma genealogia das empresas militares e de segurança privada: a trajetória da empresa DynCorp frente à formação do "mercado da força" nos Estados Unidos

- Tomaz Oliveira Paoliello

Doutor em Relações Internacionais pelo programa San Tiago Dantas (UNESP, UNICAMP, PUC-SP). Professor da Pontificia Universidade Católica de São Paulo (PUC/SP). Visiting Fellow no Latin America and Caribbean Centre; London School of Economics and Political Sciences (LACC-LSE). São Paulo, SP - BRASIL lattes.cnpq.br/9784670398428250 tomazpaoliello@gmail.com

(D) orcid.org/0000-0002-1217-4273

Para citar este artigo:

PAOLIELLO, Tomaz Oliveira. Uma genealogia das empresas militares e de segurança privada: a trajetória da empresa DynCorp frente à formação do "mercado da força" nos Estados Unidos. Tempo e Argumento, Florianópolis, v. 13, n. 32, e0112, jan./abr. 2021.

do) http://dx.doi.org/10.5965/2175180313322021e0112 


\title{
Uma genealogia das empresas militares e de segurança privada: a trajetória da empresa DynCorp frente à formação do "mercado da força" nos Estados Unidos ${ }^{1}$
}

\begin{abstract}
Resumo
As empresas militares e de segurança privada (EMSP) são um tipo de ator emergente nos debates a respeito dos conflitos contemporâneos, principalmente por conta de sua grande participação ao lado das tropas dos EUA nas Guerras do Afeganistão e do Iraque. A literatura sobre o tema em geral reagiu ao surgimento e crescimento do chamado "mercado da força", identificando o que seria um momento de gênese dessas companhias, o final da Guerra Fria ou o pós 11 de setembro. Apesar disso, ao longo do século XX, é possível identificar nos Estados Unidos um conjunto de transformações nos procedimentos militares, nas tecnologias, nas normas que regularam a terceirização e na atuação dos atores privados que conformaram o atual estado do mercado para serviços militares privados e que tornaram possível a explosão desse fenômeno a partir dos anos 1990. A opção por uma genealogia, produzida através da reconstituição do desenvolvimento da empresa DynCorp, desde suas origens no pós-Segunda Guerra Mundial até a sua participação na Guerra do Iraque, busca indicar que o atual mercado para EMSP emerge a partir de adaptações de longo prazo das empresas, e de seu principal cliente, o governo dos EUA. A associação entre as EMSP e outros atores e setores econômicos indica uma dimensão econômica dos conflitos contemporâneos relacionada não apenas aos seus fins, mas também aos meios disponíveis.
\end{abstract}

Palavras-chave: Empresas militares e de segurança privada. Estados Unidos. DynCorp. Guerra do Iraque. Guerra do Afeganistão.

\section{A genealogy of the private military and security companies: the trajectory of DynCorp towards the formation of the "market for force" in the United States}

\begin{abstract}
Private military and security companies (PMSC) are an emerging actor in debates about contemporary conflicts, mainly because of their large participation alongside US troops in the Afghanistan and Iraq Wars. The literature on the subject in general reacted to the emergence and growth of the so-called "market for force", identifying what would be a moment of genesis of these companies, the end of the Cold War or the post-9/11 period. Despite this, throughout the twentieth century it is possible to identify in the United States a set of transformations in military procedures, in technologies, in the norms that regulated outsourcing and in the private actors' behavior that shaped the current state of the market for private military services and that made the explosion of this phenomenon possible since the 1990s. The option for a genealogy, produced through the reconstitution of the development of DynCorp, from its origins in the post-World War II until its participation in the Iraq War, seeks to indicate that the current PMSC market emerges from long-term adaptations of companies and their main client, the US government. The association between the PMSC and other actors and economic sectors indicates an economic dimension of contemporary conflicts related not only to their ends, but also to the means at hand.
\end{abstract}

Keywords: Private military and security companies. United States. DynCorp. Iraq War. Afghanistan War. 


\section{Introdução}

As empresas militares e de segurança privada (EMSP) são um ator emergente nos debates a respeito dos conflitos contemporâneos. Essas empresas começaram a se revelar ao público principalmente a partir do crescimento de suas atividades nas ocupações lideradas pelos Estados Unidos da América (EUA) no Iraque e no Afeganistão e a subsequente atenção dispensada ao fenômeno pela mídia. O despertar para o tema não é descabido. Estimava-se que um em cada dez soldados em atividade na guerra do Iraque em 2003 fossem provenientes de companhias privadas (HOLMQVIST, 2005, p. 23). No ano de 2010, o número de empregados privados contratados pelo Departamento de Defesa (DdD) americano já superava em 19\% o número de “uniformizados", e essa diferença aumentou conforme foram retiradas as tropas restantes (SCHWARTZ, 2010). No ano de 2010, entre janeiro e junho, pela primeira vez na guerra do Iraque houve mais mortes de empregados militares privados do que de soldados uniformizados americanos (JACQUETTE, 2010).

A segurança como negócio foi uma das grandes forças responsáveis pela transformação dos campos de batalha contemporâneos. Hoje as operações internacionais das forças armadas de grandes potências ocorrem amparadas por uma rede ampla de serviços terceirizados. Funções que vão desde a logística, passando pela manutenção de equipamentos, serviços de tradução, até funções consideradas como o núcleo dos aparatos de defesa e segurança, como inteligência, mapeamento, treinamento de tropas e, em diversos casos, as próprias funções de combate. O caráter altamente especializado e tecnológico dos conflitos contemporâneos abriu espaço para que uma série de empresas explorassem o novo e lucrativo "mercado da força" (AVANT, 2005). Apesar de estarem intimamente associadas aos conflitos no Afeganistão e no Iraque, e à sua relação com as forças estadunidenses e britânicas, a gama de clientes das empresas é muito maior, e vai além dos Estados. ONGs, jornalistas, empresas e organizações internacionais que operam em zonas de conflitos, todos têm se valido em maior ou menor medida de segurança privada. De acordo com Avant, por exemplo, "todas as operações de paz multilaterais conduzidas pela ONU desde 1990 incluíram a presença das EMSP” (AVANT, 2005, p. 7). O aumento da 
gama de cenários, clientes e funções dessas empresas fez explodir também a produção bibliográfica sobre o tema.

Diversos autores identificam o surgimento do fenômeno das empresas de segurança privada com o final da Guerra Fria e o início dos anos 1990 (LOCK, 1999; UESSELER, 2008). Embora seja sabido que algumas empresas já existiam antes do período mencionado, para esses autores foi possível identificar o crescimento de um mercado de empresas militares privadas, com o impulso proveniente tanto da demanda quanto da oferta, a partir do início dos anos 1990 (AVANT, 2007; O`BRIEN, 2000). Grande parte da literatura produzida sobre o tema esteve condicionada pelo contexto na qual foi formulada. O resultado é que, para diversos autores, alguns fatores considerados fundamentais a princípio, acabaram se provando menos cruciais para o desenvolvimento do fenômeno. Singer (2008), uma das mais importantes referências para o estudo do tema, atribui ao final da Guerra Fria o grande impulso tanto para a demanda quanto para a oferta no mercado militar privado.

The standoff between the two superpowers ordered international politics for half a century. When the Berlin Wall fell, an entire global order collapsed almost overnight. The resultant effect on the supply and demand of military services created a 'security gap' that the private market rushed to fill. (SINGER, 2008, p. 49)

Este artigo buscará revelar as dinâmicas que possibilitaram a emergência do atual "mercado da força". O artigo utiliza o conceito de genealogia para se afastar da tentativa de identificar uma "origem" das EMSP ou do mercado para estas empresas. Pelo contrário, o propósito de uma genealogia seria demonstrar as condições que tornaram o presente possível (FOUCAULT, 1979).

Através dessa reconstituição, o artigo procura desestabilizar duas concepções contraditórias sobre os conflitos contemporâneos e as EMSP. A primeira concepção, de que as guerras atuais são as "primeiras guerras privatizadas", fato questionável em vista da trajetória da empresa DynCorp. Essa companhia está entre um seleto grupo de prestadoras de serviço para o governo dos EUA que compõem o núcleo dos serviços de terceirização de funções militares no país. Dos estimados US $\$ 138$ bilhões em contratos provenientes da 
Uma genealogia das empresas militares e de segurança privada: a trajetória da empresa

DynCorp frente à formação do "mercado da força" nos Estados Unidos

Tomaz Oliveira Paoliello

Guerra do Iraque, estima-se que US\$ 72 bilhões tenham ficado com as dez maiores empresas, ou mais de 52\% do total (SCHWARTZ, 2010).

A DynCorp pode ser um caso de estudo ideal, pois se dedicou a ampla gama de diferentes serviços que hoje estão sob os cuidados de atores privados, incluindo manutenção e logística de bases militares no exterior, serviços de manutenção e operação de equipamentos, serviços de segurança e guardacostas para diplomatas, e treinamento de forças militares e policiais nos processos de reconstrução pós-conflito. Ademais, a trajetória da empresa permite demonstrar que apesar de o final da Guerra Fria ser um ponto de inflexão importante, ele dificilmente pode ser caracterizado como o marco do surgimento das EMSP. O mesmo pode ser dito para a Guerra do Iraque.

A segunda concepção, de natureza inversa, entende que a presença crescente das EMSP nas guerras contemporâneas não apresenta nenhuma mudança na natureza dos conflitos. Alguns dos mesmos autores mencionados anteriormente (LOCK, 1999; O’BRIEN, 2000; UESSELER, 2008) descrevem a presença de mercenários como uma constante nos conflitos contemporâneos. ${ }^{2}$ A exceção seriam, portanto, as guerras modernas, quando prevaleceu uma predominância dos Estados como atores centrais dos conflitos. Como será demonstrado no presente artigo, a presença das EMSP não pode ser caracterizada em oposição à predominância dos Estados como atores da guerra por dois motivos. As empresas militares contemporâneas complementam e não competem pelas atividades de combate, que seguem sendo exercidas predominantemente por exércitos regulares, especializando-se em funções de

\footnotetext{
${ }^{2}$ As EMSP se diferenciam conceitualmente e legalmente do mercenarismo, prática condenada internacionalmente pela Convenção de Genebra. O termo "mercenário" também é evitado pelas próprias empresas, já que apresenta conotação pejorativa. De acordo com Pimentel e Paoliello (2018, p. 817-819), "as EMSP são companhias comerciais cuja forma organizacional é fundamentalmente diferente tanto dos aventureiros individuais, em busca de lucro e glória, quanto dos mercenários que recorrem ao mercenarismo como forma de sobrevivência em cenários de conflito e miséria. As EMSP são hierarquicamente organizadas como negócios legalmente registrados que competem, via de regra, em mercados de livre concorrência de alcance global, visando ao lucro. Por serem empresas legalmente constituídas, as EMSP usufruem de redes de financiamento internacional semelhantes àquelas que irrigam outros setores econômicos. Essas características diferenciam as EMSP não só daqueles mercenários que agem na obscuridade, contra a lei, mas também daquelas companhias monopolistas dos séculos XVII e XVIII, as quais criavam suas próprias leis e regras, atuando como entidades paraestatais corresponsáveis pela exploração colonial (SINGER, 2008, p.45-6; PERCY, 2007 apud PIMENTEL; PAOLIELLO, 2018, p. 817-819).
} 
apoio e consultoria. A consequência disso é que as EMSP tornam ainda mais eficaz a capacidade dos Estados de exercer poder em territórios distantes, sendo responsáveis por um acréscimo de poder, notavelmente para o caso dos EUA.

Em outras palavras, o enorme crescimento da participação de EMSP não seria ilustrado nem por uma evolução descrita como uma imagem orgânica, nem por uma mudança completa de paradigma. Na verdade, responde a transformações sociais que se acumularam ao longo da segunda metade do século XX para criar as condições do presente. Para evitar exageros interpretativos aos dois extremos, o artigo opta por ilustrar essas transformações seguindo a trajetória de uma companhia especificamente, a DynCorp. Essa história é utilizada como sinédoque, no sentido de que a trajetória de uma companhia pode ilustrar ou representar a história das demais grandes empresas ou mesmo do setor como um todo nos EUA.

O artigo está dividido em quatro partes e é ordenado cronologicamente. Uma primeira parte cobre o período pós-Segunda Guerra Mundial e formação da DynCorp na Guerra Fria, com ênfase na Guerra da Coreia. A segunda parte cobre o período da Guerra do Vietnã e as adaptações da empresa a funções de apoio militar. A terceira parte se concentra nos anos 1990 e no processo de reforma neoliberal nos EUA. Finalmente, a quarta parte cobre os conflitos do Afeganistão e do Iraque, a consolidação do contemporâneo "mercado da força", de sua ascensão ao declínio com a retirada das tropas no governo Obama. ${ }^{3}$ Além da apresentação do histórico da empresa DynCorp, cada uma das partes apresenta contextualização sobre a política externa dos Estados Unidos nos períodos estudados, particularmente em sua relação com os grandes conflitos militares que marcam essas diferentes fases.

\section{O pós-Segunda Guerra Mundial e a Guerra Fria - o primeiro ensaio de terceirização}

A grande novidade para os Estados Unidos no período do pós-Segunda Guerra Mundial foi o enorme contingente de mão de obra militar que havia se

\footnotetext{
${ }^{3}$ O autor opta por não sistematizar os acontecimentos no governo Donald Trump (2017-2020) por ser um período não encerrado até a conclusão deste artigo.
} 
formado nos anos do conflito e que seria desmobilizado. No último ano da Guerra, os Estados Unidos contavam com 12 milhões de pessoas nas Forças Armadas. Em 1947, ano em que se encerrou a desmobilização, esse número havia caído para aproximadamente 1,5 milhão. Apesar de um esvaziamento expressivo dos contingentes da Segunda Guerra, o número de soldados era ainda quatro vezes maior do que em 1939, quando as Forças Armadas dos EUA contavam com pouco mais de 300 mil homens. Embora os momentos finais de grandes guerras sejam considerados propícios para a formação de empresas prestadoras de serviços militares (SINGER, 2008), no período específico faltava também uma força de demanda que justificasse a formação de tais empresas.

Apesar de uma grande mobilização dos recursos econômicos para apoiar o esforço de guerra, a quantidade de contratados civis na Segunda Guerra era relativamente baixa. Contratados privados representavam aproximadamente 14\% da força total (HUSKEY, 2010, p.6). Além disso, existem poucos relatos de que esses contratados fossem a campo. O primeiro grande impacto em direção à terceirização de funções militares para empresas privadas se deu em 1951, com a formulação dos contract field teams (CFT). Apesar de o programa ser administrado pela Força Aérea, todos os ramos militares podem utilizar o programa. De fato, foi isso que ocorreu ao longo do tempo, já que o Exército e a Marinha também utilizam CFT para a manutenção de seus equipamentos, principalmente aeronaves.

A data de formulação do programa, 1951, coincide com o período da Guerra da Coreia, a primeira grande operação militar estadunidense no período da Guerra Fria. Apesar de a Guerra da Coreia ter envolvido uma porcentagem maior de contratados privados do que a Segunda Guerra Mundial, ainda eram raros os relatos de funcionários civis mortos em combate. Esse dado significa que poucos contratados civis estivessem, de fato, operando junto das tropas. A maior parte das atividades de EMSP no período consistiam em serviços de aviação. O diferencial para a Guerra da Coreia foi a grande quantidade de contratados locais, que prestavam serviços in loco para as tropas estadunidenses. Isso ajuda a explicar o enorme número de civis, se compararmos com a Segunda Guerra (DPAP, 2015). A razão entre civis e tropas regulares demonstra o impacto de 
demanda gerado por esse conflito. Na Coreia, a participação de contratados privados chegou a compor $25 \%$ do total das forças no país, como pode ser visto na figura 1.

Figura 1 - Crescimento na quantidade de contratados privados das Forças Armadas dos EUA, por conflito

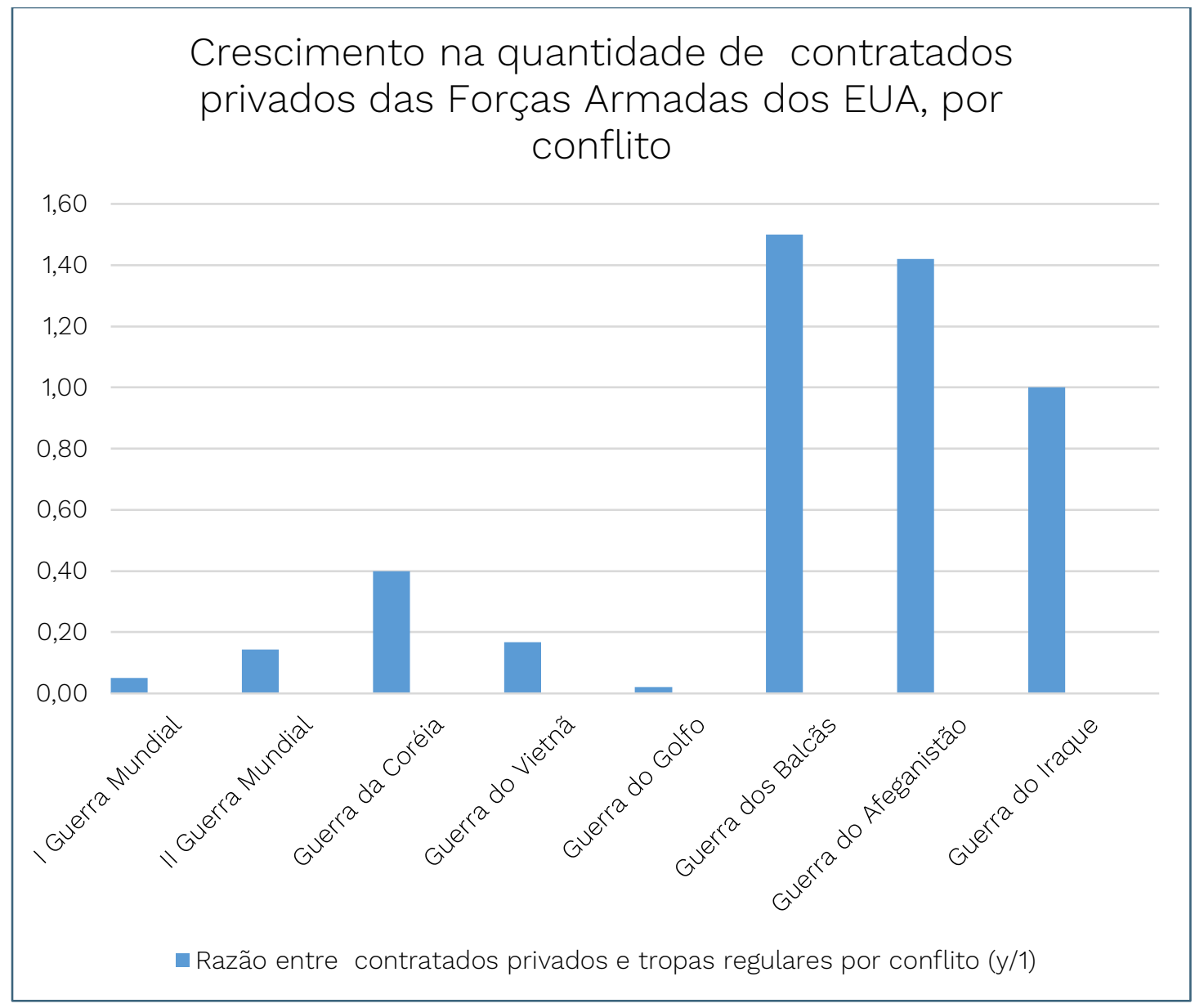

Fonte: (LUSE, MADELINE, SMITH, STARR, 2005).

A origem da contemporânea DynCorp International LLC está associada a duas empresas fundadas em 1946, a Land-Air, Inc., e a California Eastern Airways (CEA). Se é nessas duas empresas que se encontram os primórdios da contemporânea DynCorp International, é também neste período que podem ser identificados os primórdios da nascente indústria de serviços militares que se formou a partir do final da Segunda Guerra Mundial, principalmente nos Estados Unidos. Reiterando a justificativa da escolha do estudo desta empresa especificamente, acompanhar a evolução da companhia ao longo do tempo é 
também vislumbrar de que maneira se constituiu o mercado para as empresas militares que se associaram a setores do Estado nos EUA.

A CEA foi uma empresa fundada por Jorge Carnicero, em sociedade com pilotos veteranos da Segunda Guerra Mundial, especializada em transporte aéreo de cargas. A empresa foi uma das primeiras companhias especializadas em transporte aéreo de cargas comerciais. A CEA começou com voos na Califórnia, mas em menos de um ano já voava em todo o território americano. A empresa adquiriu suas primeiras aeronaves da Força Aérea dos Estados Unidos. Ao final da Segunda Guerra Mundial, a Força Aérea vendeu o excedente de aeronaves utilizadas no conflito, incluindo as aeronaves de transporte militar Douglas C-54, derivadas da aeronave comercial Douglas DC-4. Os aviões C-54 tinham flexibilidade para conversão em veículos comerciais, ou para que continuassem em uso militar, o que permitiu que a CEA operasse contratos tanto para as Forças Armadas quanto comerciais (DEAN, 2008).

Apesar do início associado a operações comerciais, a CEA cresceu através da prestação de serviços às forças armadas estadunidenses. Já que tanto as aeronaves quanto os pilotos da companhia tinham histórico e capacidade de emprego militar, a empresa explorou, desde cedo, a possibilidade de associação com as Forças Armadas. A CEA foi uma das empresas que participou do Korean Airlift, operação da força aérea estadunidense que abasteceu as tropas por via aérea durante a Guerra da Coreia. A operação envolveu a coordenação de aeronaves militares e civis para apoio logístico das tropas durante o conflito. A CEA operou voos transpacíficos depois de vencer uma concorrência do governo em 1950. O contrato foi encerrado em 1953, ano em que se encerra o conflito na Coreia. Depois do final do contrato, a CEA continuou operando voos comerciais e de cargas entre a Califórnia e Tóquio, no Japão, e entre a Califórnia e Manila, nas Filipinas (DEAN, 1998, p. 107-108).

Já a Land-Air era uma empresa especializada em manutenção de aeronaves. A partir de sua fundação, a empresa passou a operar bases de mísseis da Força Aérea dos EUA e prestar serviços de operação e manutenção de aeronaves modificadas para diferentes agências do governo estadunidense. A empresa detinha dois importantes conjuntos de contratos com o governo dos 
EUA. O contrato mais importante da empresa era um CFT firmado junto à Força Aérea. Através desse tipo de contrato, a Land-Air ficava responsável pela manutenção das aeronaves militares. Um segundo grupo de contratos era de gerenciamento e manutenção de bases aéreas. O principal deles era de operação da White Sands Missile Range, a maior instalação militar dos EUA, localizada no Novo México. A base foi principalmente utilizada como campo de testes militares, e foi o local da primeira explosão de uma bomba atômica, em 1945.

As fundações da CEA e da Land-Air são semelhantes à formação de uma série de empresas no período do imediato pós-Segunda Guerra. Excedentes de material militar e de força de trabalho militar desmobilizada criam um ambiente favorável à abertura de negócios que combinem essas duas ofertas. Diversos dos autores interessados no surgimento das EMSP associam o fenômeno ao final da Guerra Fria, momento em que os dois fatores de oferta aqui mencionados também estiveram presentes. A origem da Dyncorp sugere uma hipótese mais abrangente, derivada de Peter Lock (1999), que sustenta que os momentos de crescimento e transformação do mercado para empresas militares estão associados à ocorrência de grandes conflitos, em geral ao encerramento de momentos de expansão da militarização. Ou seja, o final da Guerra Fria é fator explicativo importante, mas não particular, para o surgimento das EMSP, como demonstra o final da Segunda Guerra Mundial.

A particularidade da Segunda Guerra Mundial como fator explicativo para o surgimento de empresas associadas a funções militares pode estar ligada à profundidade do impacto dos gastos militares no período. Durante a Guerra, no ano de 1944, os gastos militares dos EUA chegaram a 41\% do PIB, e se mantiveram próximos de 10\% nos vinte anos seguintes ao final da Guerra. Um novo pico de 15\% do PIB com gastos militares ocorre durante a Guerra da Coreia. Para fins comparativos, o aumento nos gastos militares durante o governo de Ronald Reagan, nos anos 1980, alcançou 6,8\% do PIB, até chegar a 3,5\% no ano 2000. Isso significa que em nenhum outro momento da história a economia americana esteve tão associada aos gastos militares. Ademais, o nível alto de gastos militares no período pós-Segunda Guerra ajuda a explicar também a viabilidade de empresas militares no período. 
A história da união entre CEA e Land-Air é apresentada em duas versões. De acordo com informações fornecidas pela própria DynCorp, a Land-Air foi comprada pela CEA em 1950 (DYNCORP, 2020). Outras fontes, como Dean (2008) apontam que a CEA passou por um processo de falência em 1948. Nesse momento, a CEA é desmembrada. Os ativos da companhia teriam sido comprados pela Slick Airways, empresa aérea que também utilizava aeronaves sobressalentes da Segunda Guerra Mundial e pilotos veteranos do conflito, ou seja, com perfil bastante similar ao da CEA. Já o restante da companhia, incluindo o nome CEA teria sido adquirido pela Land-Air (DEAN, 2008, p. 175).

Seja qual for a versão precisa da história, a união entre a CEA e a Land-Air é o primeiro ato de uma trajetória de fusões e aquisições que tornaram a DynCorp a empresa que é hoje. É importante destacar que, no início dos anos 1950, a empresa que viria a se tornar a DynCorp já tem um tamanho relevante. A compra da Land-Air permitiu que a CEA pudesse participar de contratos mais complexos no setor aéreo e aeroespacial. Nesse momento, a CEA detinha uma série de contratos com a Força Aérea dos EUA, que variavam desde transporte de cargas e mantimentos para as operações militares, até a operação de bases de mísseis nucelares. A área de expertise da empresa seguia sendo a manutenção de aeronaves, mas com foco cada vez mais específico nas áreas de tecnologias e sensores. Mais do que isso, a partir da fusão das duas empresas, a CEA ganhou capacidade de operar tecnologias avançadas que fariam parte da ampla transformação tecnológica que se operaria durante os anos da Guerra Fria.

A partir dessa primeira fusão, a trajetória de crescimento da empresa estará associada à ampliação da quantidade de funções, principalmente num processo de aquisição de importantes contratos de prestação de serviços junto ao governo dos EUA. A busca por diversidade de serviços na trajetória de crescimento da DynCorp não esteve associada a um processo de especialização em funções militares. Pelo contrário, até os anos 1980, o processo que se observa é inverso, de busca pela capacidade de atuar em novos setores. Num primeiro momento, é possível perceber um processo de centralização, no qual diversas empresas são agrupadas sob uma mesma organização. Na seção seguinte será possível observar ações no sentido contrário, de especialização de funções. 
Em 1952, a CEA adquiriu a empresa Air Carrier Service Corporation (AIRCAR), especializada na venda de partes de aeronaves e partes avulsas para companhias aéreas e governos estrangeiros. Os registros encontrados da operação da AIRCAR dão conta de que a empresa se especializava na compra de aviões norte-americanos, sua posterior reforma e adaptação para venda a clientes de fora dos EUA. A aquisição da AIRCAR coincide com a gradual diminuição dos voos sob o nome California Eastern, e a especialização da empresa em serviços de leasing de aeronaves (DEAN, 2008, p. 108).

Apesar de não haver informação abundante sobre a empresa, um dos casos elucidativos sobre o papel da companhia é relacionado ao Brasil, presente num processo judicial de 1968. No final dos anos 1950, Jorge Carnicero, fundador da CEA e executivo chefe da AIRCAR, foi sócio de uma companhia aérea no Brasil junto com o empresário Haroldo Buarque de Macedo. Essa companhia foi vendida, em 1961, para a Real S/A Transportes Aéreos. Na venda, a AIRCAR se tornou a representante da Real para a compra de aeronaves no exterior. De acordo com o contrato firmado, a Real deveria adquirir $85 \%$ de suas aeronaves junto à empresa. A AIRCAR termina por adquirir aeronaves da American Airlines e repassá-las à Real, demonstrando a transformação nas atividades da empresa.

Até esse momento, o grupo comandado por Jorge Carnicero se especializou em serviços associados à aviação. No entanto, o processo apresenta uma trajetória de concentração de diversas capacidades associadas ao setor aéreo. Ao longo dos anos 1950, as empresas do grupo se especializaram em prestação de serviços para aviação civil e militar. A CEA era uma das poucas empresas capazes de fazer adaptação de aviões que não era também uma fabricante de aeronaves. Pelo contrário, a empresa se especializou em adquirir aeronaves usadas e adaptá-las para novos clientes. O caso da relação entre a Real e a AIRCAR demonstra uma faceta civil, mas no mesmo período existem relatos de que a CEA ficou responsável pela instalação de sensores e radares em aeronaves do exército para fins de espionagem (DEAN, 2008). O papel dos mecânicos da empresa que operavam em bases militares se transformaria, ao longo dos anos 1960, quando passaram a operar também em palcos de conflitos. 


\section{A Dynalectron Corporation e a Guerra do Vietnã (1961-1987)}

Em janeiro de 1961, o então presidente dos EUA, Dwight Eisenhower, pronunciou seu famoso discurso de despedida. Nele, o presidente exortava a nação a se precaver contra a crescente influência de setores da indústria armamentista associados a setores do governo. De acordo com Eisenhower, a formação de um “complexo militar-industrial” poderia ameaçar as liberdades e os processos democráticos estadunidenses (EISENHOWER, 1961). Se o alerta no discurso de Eisenhower foi, até hoje, usado como indicativo do poder de influência da indústria militar nos Estados Unidos, a data do pronunciamento é especialmente relevante para o presente estudo.

No mesmo ano em que Eisenhower prevenia os norte-americanos quanto ao perigo do surgimento do "complexo militar-industrial", em 1961, a CEA se torna a Dynalectron Corporation. A criação da nova marca significa que a empresa também se preparava para novos tempos. O novo nome foi escolhido a partir de mais de cinco mil sugestões dos funcionários da empresa. A ideia era atualizar o nome para um conceito abrangente, que representasse o crescente número de funções desempenhadas pela empresa, envolvida em setores mais diversas do que serviços aéreos, e que havia crescido para muito além da Califórnia (DYNCORP, 2015). Os anos 1960 seriam especialmente proveitosos para a empresa, que se tornou um dos principais prestadores de serviços para as Forças Armadas dos Estados Unidos no Vietnã.

A Dynalectron abandonou completamente os serviços de linhas aéreas que haviam sido a base da formação das empresas do grupo no pós-Segunda Guerra. Os aviões da empresa, a maioria em contratos de lease para outras companhias aéreas, foram vendidos até 1961 (DEAN, 2008, p. 109). A prestação de serviços militares se tornaria o núcleo dos seus contratos, já que a escalada da Guerra do Vietnã fez com que esse mercado se tornasse ainda mais interessante. Através de seus contratos de CFT junto à Força Aérea, a Dynalectron garantiu enorme presença no conflito que se desenvolvia. A grande dependência de apoio aéreo no Vietnã demandou também grande quantidade de engenheiros e mecânicos para manutenção de aeronaves, principalmente helicópteros. A empresa era também responsável pela manutenção de veículos 
e equipamentos para o exército. Além das operações dentro dos aeroportos e bases aéreas, a empresa se instalou de maneira independente em vinte e seis localidades no Vietnã.

The U.S. Army Mobility Equipment Command also awarded a $\$ 5$ million contract to Dynalectron Corporation of Fort Worth, Texas, to provide maintenance and repair parts support. In May 1969, the firm began setting up shop at twenty-six locations in Vietnam, and its employees, numbering between 125 to 200 technicians, accomplished all unit-level maintenance and ran small repair parts distribution points at job sites for the 18th and 20th Brigade units. (TRAAS, 2010, p. 419)

De acordo com documentos de contabilidade, para o período de auge da Guerra do Vietnã, a Dynalectron chegou a contar com 1.056 funcionários no país em 1969, e os contratos da empresa somados chegaram a mais de US\$18 milhões em 1970 (JLRB, 1970, p. 252). Apesar da especialização em serviços para as Forças Armadas, a Dynalectron participou de outras funções no esforço militar no Vietnã. Durante os anos da guerra, a empresa manteve um contrato junto à USAID para fornecimento de partes e manutenção para os equipamentos de construção empregados no Vietnã. Isso significa que os mecânicos da empresa e os setores de aquisições e distribuição eram responsáveis por toda a gama de equipamentos utilizados pelos EUA no Vietnã, sejam de uso civil ou militar. No entanto, a Dynalectron não era a única a prestar esse tipo de atividade. Embora a empresa tenha sido a única a fornecer técnicos e mecânicos na Guerra do Vietnã no ano de 1966, a partir de 1967, a Lear Sieglertambém passa a fazer parte do conflito. A partir de 1968, também a Lockheed se torna uma prestadora de serviços no conflito (JLBR, 1970, p. 253). A Vinnell também é igualmente citada como prestadora de serviços durante o conflito (TRAAS, 2010). Já é possível perceber, para o período da Guerra do Vietnã, o crescimento de um ainda incipiente mercado para as EMSP.

Em 1976, a Dynalectron, até então sediada em Fort Worth, no Texas, muda sua sede para o município de McLean, no estado da Virginia. O município é contíguo a Washington, District of Columbia, capital dos EUA. É em McLean que estão sediadas diversas agências do governo federal, notavelmente a CIA. McLean é também sede de diversas outras grandes empresas que se beneficiam da proximidade da localidade com a capital federal. Essa mudança pode ser 
considerada estratégica conforme crescem as operações militares da empresa em detrimento de operações comerciais civis. A mudança já indica a tendência de crescimento da utilização de contratados privados nos conflitos, que irá se consolidar ao longo dos anos 1980 e explodir nos anos 1990.

Conforme é possível visualizar na figura 1, a situação dos contratados privados das Forças Armadas dos EUA se modifica durante a Guerra do Vietnã. Nesse conflito, a razão entre contratados privados e tropas oficiais (1/6) fica superior à da Segunda Guerra Mundial (1/7), mas é consideravelmente menor do que na Guerra da Coreia (1/2.5). No entanto, o impacto é mais notável, pois os contratados privados passam a operar incorporados às forças oficiais. Conforme já descrito, a Dynalectron passa a operar em 26 diferentes localidades no Vietnã. Listas dos funcionários da empresa mortos em serviço no exterior são facilmente acessíveis. ${ }^{4}$ A Dynalectron possuía também um decalque militar próprio, para afixação nos uniformes. Esse fato pode parecer prosaico, mas revela que a participação de funcionários de empresas privadas já ocorria de maneira integrada às Forças Armadas. A Dynalectron era tratada, no Vietnã, como mais uma das divisões expedicionárias.

Autores que tratam do tema (LUSE et al., 2005) cogitam que a principal novidade para a expansão das atividades de contratados terceirizados a partir da Segunda Guerra seja a exigência tecnológica, e consequentemente, uma crescente dependência dos fabricantes de materiais e equipamentos. Equipamentos atuais e atualizados deveriam ser entregues com rapidez, muitas vezes sem que os funcionários das Forças Armadas pudessem obter treinamento para operá-los. Essa hipótese condiz com uma explicação funcionalista da sistematização criada por Kruck (2013). De acordo com esta hipótese, o Estado estaria buscando no mercado capacidades das quais ele próprio não poderia dar conta.

Os autores que tratam da importância de contratados no período já chegam a sugerir uma outra hipótese, a percepção de que contratados privados corriam os mesmos riscos do que soldados oficiais em campo e, no entanto, não

Para acessar a lista de funcionários da Dynalectron que estiveram no vietnã: https://aad.archives.gov/aad/display-partial- 
fazem parte das contas de baixas militares (LUSE et al., 2005). Essa hipótese enquadraria o estímulo para a terceirização no campo das explicações políticoinstrumentalistas dentro da mesma sistematização de Kruck (2013). Ou seja, o Estado buscaria a terceirização para ampliar sua margem de manobra e para conseguir evitar arcar com os custos humanos de guerras, que, principalmente no caso do Vietnã, se tornavam crescentemente impopulares.

Podemos perceber, ao longo do período da Guerra Fria, o número crescente de contratados privados pelas Forças Armadas dos EUA, e a integração cada vez maior desses contingentes às forças regulares. Conforme podemos observar na figura 1, a proporção de contratados privados em relação às tropas oficiais tem tendência crescente, com a Guerra da Coreia como uma exceção, por conta da enorme quantidade de contratados locais. Uma segunda exceção, a Guerra do Golfo, é o prelúdio de um choque impressionante nas quantidades de funcionários de EMSP que passarão a fazer parte dos contingentes militares norte-americanos a partir da Guerra dos Balcãs.

\section{O choque neoliberal: A DynCorp e a formação do contemporâneo "mercado da força" (1987-2003)}

O final da Guerra Fria foi saudado como um momento de retração em gastos militares que poderiam ser revertidos para outros fins. O chamado "dividendo da paz" foi traduzido, num primeiro momento, como a possibilidade de extensos cortes de pessoal que se reverteriam também em economia de gastos militares. Se o projeto de um dividendo da paz foi utilizado pelo presidente George H. W. Bush em sua campanha, foi de fato na gestão de Bill Clinton que ele se concretizou. Após um leve incremento de gastos militares entre 1985 e 1990, principalmente devido à Guerra do Golfo, os gastos passam a cair ano após ano, até uma baixa histórica em 1996.

Nas duas figuras a seguir (Figura 2 e 3), é possível perceber a tendência de diminuição de gastos militares e de pessoal militar no período do pós-Guerra Fria. Os gastos militares dos Estados Unidos crescem ininterruptamente de 1974 até um pico em 1990 quando atingem aproximadamente US\$ 306 bilhões. A partir daí, recuarão até aproximadamente US\$270 bilhões em 1996. Uma leve tendência de retomada dos gastos ocorre até 2002, quando sofrerão o grande 
impacto das políticas de segurança traçadas no pós 11 de setembro. Isso significa uma redução de mais de 15\% num período de seis anos (SIPRI, 2020).

Figura 2 - Gastos militares dos EUA, por ano

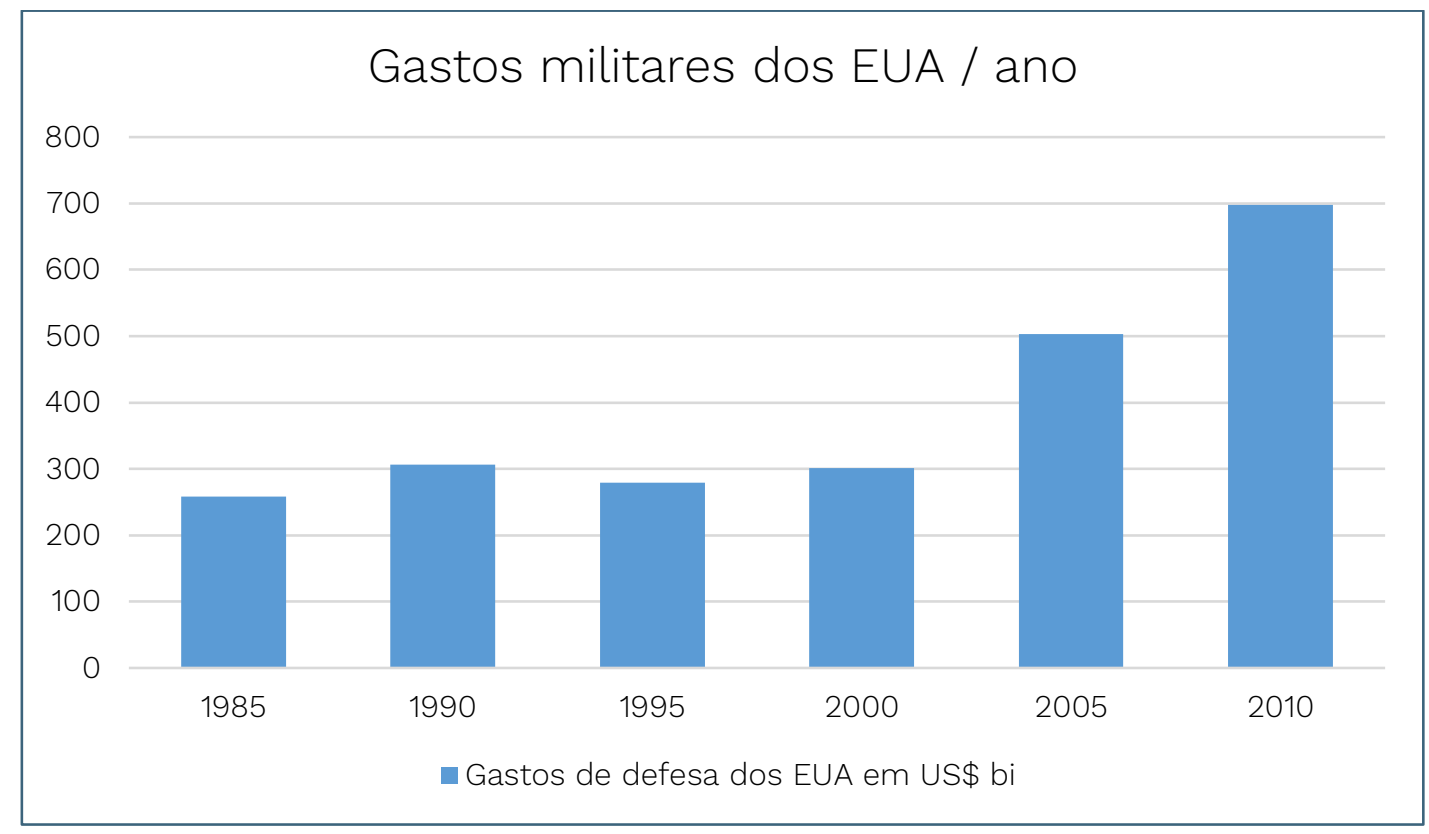

Fonte: (SIPRI, 2020).

Figura 3 - Pessoal militar total da ativa nos EUA, por ano

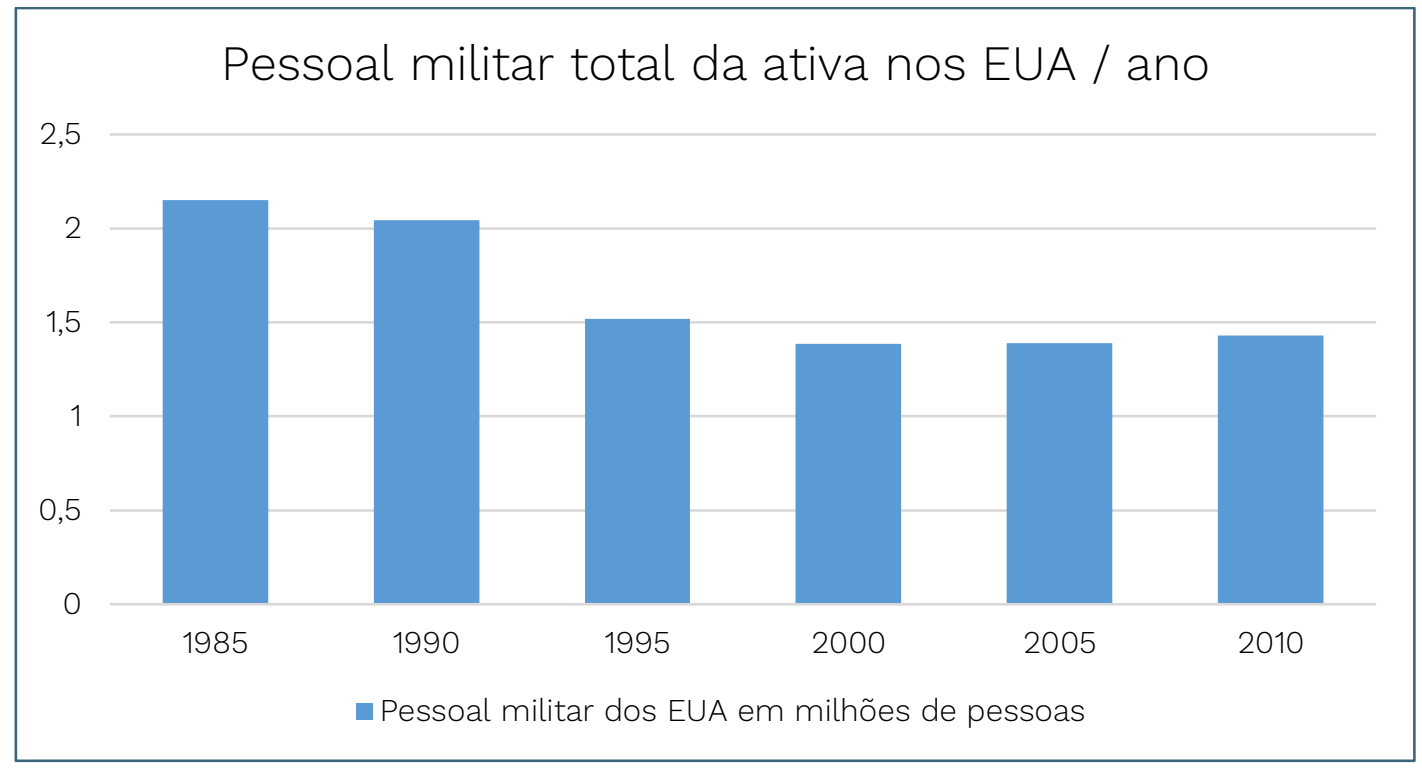

Fonte: (COLEMAN, 2015).

A redução na quantidade do efetivo militar entre 1985 e 2000, o patamar mais baixo no período considerado, é ainda maior: quase 36\% para o período de 15 anos. A redução de pessoal militar acontece em ritmo mais acentuado do que 
as reduções nas quantias de gastos militares anuais. Isso quer dizer que a proporção de gastos per capita das Forças Armadas dos EUA cresce no período, mesmo que os gastos totais diminuam. Se considerarmos a hipótese de que as EMSP se formam em momentos de crescimento da disponibilidade de pessoal militar desocupado, certamente a década de 1990 se enquadra nesse contexto.

Em 1987, a Dynalectron mudou seu nome para DynCorp. Assim como quando assumiu o nome Dynalectron, em 1961, a reinvenção da marca estaria associada ao ingresso da empresa numa nova fase. A Dyncorp havia se tornado o quarto maior contractor do setor elétrico nos Estados Unidos. Os contratos de aviação e de defesa também representavam fatia importante das receitas da empresa. Em uma nova reestruturação, a empresa formou duas grandes divisões, Government Services e Comercial Aviation Services (DYNCORP, 2020).

A mudança de nome e posterior reestruturação estavam articuladas a duas tendências que teriam impacto importante nas operações da empresa. Em primeiro lugar, a percepção de que os serviços elétricos e eletrônicos gradualmente cederiam espaço para os serviços de computação e TI, com o avanço da difusão da tecnologia de computadores. Isso significa que a principal fonte de receitas da empresa, o setor elétrico, estaria ameaçada no médio prazo. Em segundo lugar, o contexto que se antecipava em 1987 era de desconstrução do sistema da Guerra Fria e um reordenamento dos serviços prestados aos militares. A previsão, então, era de que o "dividendo da paz" significaria uma diminuição das receitas dos prestadores de serviços às Forças Armadas. As duas previsões levaram a companhia a se concentrar, portanto, numa área que anunciava crescimento (TI), e se afastar dos contratos de segurança. O plano era que, em 1995, a empresa tivesse aproximadamente "apenas" 60\% de seus contratos relacionados ao setor de defesa (FUNDINGUNIVERSE, 2015).

A DynCorp passou a investir agressivamente no setor de TI. Em 1990, a empresa criou um setor de Applied Sciences para gerenciar o que se tornaria sua principal área de expansão. No entanto, paralelamente à expansão da DynCorp no setor de TI, cresciam as atividades da empresa em serviços militares. Três funções se destacam no período, o contrato LOGCAP, de logística das forças armadas; os contratos com o Departamento de Estado (DdE) para combate às drogas na Colômbia; e para treinamento das forças de segurança pública na 
Uma genealogia das empresas militares e de segurança privada: a trajetória da empresa DynCorp frente à formação do "mercado da força" nos Estados Unidos

Tomaz Oliveira Paoliello

Bósnia. Apesar de um mercado promissor para serviços terceirizados militares, a aposta da DynCorp seguia sendo o setor de TI. Mesmo com grande investimento, em 1996, apenas 20\% das receitas da empresa eram provenientes do setor de TI. Se a aposta de futuro era o setor de informática, o presente indicava a tendência de crescimento de um novo e amplo mercado para as EMSP.

A primeira explicação importante para a diminuição nos contingentes militares sem reflexo direto nos gastos, como é possível observar nas figuras 2 e 3 pode ser atribuída ao contrato LOGCAP. ${ }^{5}$ Através desse contrato, uma enorme quantidade dos cargos de logística, que faziam parte das funções de militares regulares ativos passaram para a iniciativa privada. As mudanças internas no LOGCAP, contrato firmado pela primeira vez em 1988, também explicam por que a Guerra do Golfo não apresenta a mesma proporção de funcionários terceirizados que as guerras subsequentes.

Inicialmente, o objetivo era terceirizar funções de construção e reforma circunstanciais, e, portanto, sem nenhuma relação com os grandes conflitos. Os contratados privados na Guerra do Golfo seguiam sendo do mesmo tipo dos que foram utilizados na Guerra do Vietnã, mecânicos e técnicos especializados. Quando é assinado o LOGCAP I, com a empresa KBR, em 1992, ele toma a forma

\footnotetext{
O Logistics Civil Augmentation Program (LOGCAP) é um programa do Exército dos Estados Unidos formulado com o intuito de ampliar sua capacidade operacional, através da privatização e terceirização de funções que não sejam parte do seu núcleo de especialidades. O projeto havia sido planejado originalmente como forma de permitir reação rápida em casos de emergências ou de operações com tempo reduzido de planejamento. O que o LOGCAP veio a significar de fato é que a grande maioria dos serviços de logística e provisão das Forças Armadas em operações fora do território americano, como transporte, correspondência, lavanderia e alimentação, ou seja, o conjunto amplo de funções de manutenção das bases militares, passaram a fazer parte dos contratos com empresas privadas.

O contrato LOGCAP foi ativado pela primeira vez em 1988, quando a United States Army Corps of Engineers (USACE) terceirizou a construção de oleodutos no sudeste asiático. Naquele momento, o intuito do programa era a terceirização de obras e reformas anteriormente formuladas pelo corpo de engenheiros do exército.

O conceito atual do LOGCAP foi firmado pela primeira vez em 1992. O contrato foi assinado depois de uma concorrência na qual a empresa Brown \& Root Services Corporation, atual KBR foi selecionada. A KBR passou a operar o contrato naquele mesmo ano, provendo apoio às tropas da Missão de Paz das Nações Unidas na Somália. De acordo com a KBR, a empresa operou dentro do LOGCAP para prestar apoio logístico para tropas na Bósnia, Kosovo, Macedônia, Hungria, Arábia Saudita, Haiti, Itália e Ruanda. Em 1996, o controlador do LOGCAP passou a ser a Army Material Command, ou seja, passou a representar de maneira mais explícita o setor de logística (KBR, 2015).

A DynCorp recebeu o contrato LOGCAP II pela primeira vez em 1997, através de uma concorrência aberta. A DynCorp operou esse contrato de maneira exclusiva entre 1997 e 2001. No período, a DynCorp ficou responsável pela logística das tropas norte americanas nas Filipinas, Guatemala, Colômbia, Equador, Timor Leste e Panamá.
} 
Uma genealogia das empresas militares e de segurança privada: a trajetória da empresa DynCorp frente à formação do "mercado da força" nos Estados Unidos

Tomaz Oliveira Paoliello

de um amplo projeto de terceirização de todas as funções de logística e manutenção das Forças Armadas. Deste momento em diante, todas as grandes operações militares estadunidenses fora de seu território passarão a contar com uma ampla rede de contratados privados. No entanto, o LOGCAP não é o único dispositivo que explica as transformações do período que geram a força para o crescimento do mercado para as EMSP.

Apesar dos cortes de gastos descritos explicitamente como militares, outros tipos de gastos com EMSP passaram a ser canalizados sem que fossem classificados como gastos militares ao longo dos anos 1990. O DdE, departamento de relações exteriores, se tornou um grande cliente das EMSP, com destaque particular para a DynCorp. Várias das funções que foram historicamente reservadas às Forças Armadas passaram a ser também exercidas pelo DdE. Isso quer dizer que a dinâmica de encolhimento no orçamento militar pode significar apenas uma mudança nos canais e na rubrica para essas verbas, que passaram a ser destinadas à diplomacia.

A grande presença de diplomatas e funcionários em zonas de risco fez crescerem também os orçamentos para gastos com guarda-costas, um dos setores de especialidade da DynCorp. As situações de risco podem ser associadas à presença de diplomatas em zonas de conflito, seja por conta das ocupações militares dos EUA, seja por conta das missões de paz da ONU. Mas podem ser também associadas ao fato de que as embaixadas estadunidenses se tornaram um alvo visado para atentados terroristas, que elevam a percepção de risco e a oportunidades de negócios para empresas de segurança privada. 0 contrato WPPS, ${ }^{6}$ assinado pela primeira vez em 2000, terceirizou os serviços de

\footnotetext{
Em 2000, o Boureau of Diplomatic Security reformulou sua política de contratações de empresas através do contrato Worldwide Personal Protective Services (WPPS). A concorrência foi vencida pela DynCorp, que se tornou a fornecedora exclusiva de seguranças privados para a diplomacia americana. No período, além de prestar segurança para as autoridades norteamericanas no exterior, a empresa também forneceu seguranças para líderes de regimes apoiados pela política externa dos EUA. Em 2005, o WPPS teve que ser reformulado. No período entre 2000 e 2005, a demanda por seguranças privados explodiu depois da invasão do Iraque e da instalação da gigantesca embaixada em Bagdá, que emprega mais de 15 mil pessoas. A nova concorrência do WPPS premiou três empresas, a Triple Canopy, a U.S. Training Center, parte da Xe (então Blackwater) e a DynCorp International. A parte principal do contrato no Iraque ficou a cargo da Blackwater. Em 2007, num dos casos de maior repercussão internacional sobre as EMSP, funcionários da Blackwater operando no âmbito do contrato WPPS abriram fogo na praça Nisour, em Bagdá, matando 17 pessoas. A repercussão do caso e consequente investigação desgastaram a empresa, até que em 2009 a DynCorp incorporou as funções.
} 
proteção até então fornecidos pelo Boureau of Diplomatic Security, que se tornou o operador do contrato. O contrato tinha valor total de US\$3,6 bilhões para um período de cinco anos a partir de 2005, e subiu para quase US\$10 bilhões para o período de cinco anos iniciado em 2010 (ISENBERG, 2010, p. 30). Esses valores são parte do orçamento do DdE e não da Defesa, e, portanto, não aparecem como gastos militares, mesmo que empreguem pessoal para cumprir funções militares.

Apesar da importância dos serviços de proteção pessoal, o caso mais evidente do ganho de capacidade do DdE como ator militar são as funções associadas às missões de paz, com ênfase para os projetos de CivPol e de treinamento de forças policiais. Apesar de parecer contraditório que forças de segurança pública sejam treinadas com capacidades militares, a criação dos projetos de reforma no setor de segurança (RSS) fez surgir uma demanda para esse tipo específico de serviço. As quantias de ajuda militar e policial dos Estados Unidos subiram de US\$342 milhões em 1997, em grande parte canalizados para o plano Colômbia, para quase US\$ 23 bilhões em 2007, um valor 65 vezes maior. ${ }^{7}$

Uma das grandes oportunidades de negócios para as EMSP, ao longo dos anos 1990, foram os projetos de RSS. O conceito, desenvolvido principalmente pelos organismos doadores do Reino Unido, acabou se tornando peça fundamental dos projetos de statebuildinge peacebuilding. O conceito, conforme definido pela OCDE, engloba um projeto amplo de assistência para reforma dos sistemas policiais, militares e jurídicos em países afetados.

[...] the transformation of the "security system" - which includes all the actors, their roles, responsibilities and actions - working together to manage and operate the system in a manner that is more consistent with democratic norms and sound principles of good governance. (OECD, 2007, grifo do autor)

As RSS se tornaram uma maneira de reconstruir as capacidades policiais de regiões com altos índices de criminalidade, ou com sistemas policiais e legais frágeis ou corruptos. Mas se tornaram também correias de transmissão para práticas, valores e objetivos das políticas externas dos países doadores. De 
acordo com McFate (2014), a missão da DynCorp na Libéria incluía treinamento dos policiais e soldados do país em técnicas de contra-insurgência e contraterrorismo. Sedra considera que esse processo possa ser identificado com o conceito de militarização já que, em geral, as EMSP contratam pessoal militar para treinamento de policiais.

[...] the growing role of private security companies (PSCs) in the SSR field has contributed to what some see as a militarization of the concept, as these agencies tend not to have strong capacity in civilian aspects of the field. Outsourcing also raises pressing questions about transparency and accountability, as regulations, standards and domestic laws that bind governments often don't apply to non-state actors. (SEDRA, 2010b, p. 115)

Todos os processos observados ao longo dos anos 1990 ganham massa crítica, e ganharão um novo tamanho na década seguinte. A enorme elevação de gastos observada entre o ano 2000 e 2010 (Figura 2), somada à manutenção dos efetivos de militares nos EUA (Figura 3) é o indício de que, a partir dos anos 2000, o "mercado da força" atinge seu auge. Em 2000, a DynCorp dividiu suas atividades em duas empresas, refletindo o crescimento da prestação de serviços internacionais da companhia. A primeira delas, DynCorp International LLC, concentraria as operações internacionais da DynCorp. A segunda, DynCorp Technical Services LLC, continuaria a operar os contratos domésticos da empresa. Nesse momento é possível reiterar a importância da terceirização das funções militares.

A DynCorp International, nova divisão da empresa, ficaria responsável exclusivamente pelo que se considera hoje como uma EMSP. A DynCorp Technical Services operaria as funções de TI. Em ambos os casos, o governo federal continuaria sendo o principal cliente, dentro e fora do território americano. O enorme crescimento dos contratos para as EMSP, ao longo dos anos 1990, vai exercer um impacto importante sobre a DynCorp. A empresa que até então buscava se expandir através da aquisição de empresas menores, vai mudar seu perfil. A partir de 2003, outras empresas ainda maiores buscarão adquirir a DynCorp para ingressar no promissor mercado para as EMSP. 


\section{A financeirização das EMSP: as Guerras do Afeganistão e do Iraque como balcão de negócios}

Um documento específico, a Circular A-76 ajuda a elucidar a história da terceirização de funções militares nos EUA, já que é esse documento que determina a obrigação da contratação de serviços privados pelo Governo Federal dos EUA. Os precedentes da circular são uma série de documentos emitidos pelo escritório de orçamento do governo federal ao longo do governo Eisenhower, nos anos 1950, que determinavam que o governo não deveria competir com empresas que prestassem funções similares. Cabe lembrar que foi exatamente ao longo da gestão Eisenhower que os primeiros contratos de terceirização de serviços militares, os CFT foram assinados.

The Bureau of the Budget, predecessor of OMB, issued, in 1955, Bulletin Number 55-4, which stated: "It is the general policy of the administration that the Federal Government will not start or carry on any commercial activity to provide a service or product for its own use if such product or service can be procured from private enterprise through ordinary business channels." (THE BUREAU OF THE BUDGET, 1955 apud HALCHIN, 2007, p. 6, grifo do autor)

A Circular A-76 foi um documento emitido pelo Office of Management and Budget (OMB), em 1966, durante o governo Lyndon Johnson. A circular condensava uma série de decisões anteriores sobre a contratação de serviços privados pelo governo. A ideia principal era que, para casos em que o governo prestasse serviços que eram também disponibilizados pelo mercado, as empresas estatais deveriam competir em igualdade com as empresas privadas. Em 1979, a Circular A-76 volta a ser revisada, com uma nova atualização de seu texto. O parágrafo que apoia o documento, a peça central da lógica que ampara o ímpeto pela terceirização constata que:

In a democratic free enterprise economic system, the Government should not compete with its citizens. The private enterprise system, characterized by individual freedom and initiative, is the primary source of national economic strength. In recognition of this principle, it has been and continues to be the general policy of the Government to rely on competitive private enterprise to supply the products and services it needs. (HALCHIN, 2007, p. 7)

A associação entre a inciativa privada, a democracia e a liberdade se manteriam em todas revisões posteriores do documento. Apesar disso, a circular 
ainda passaria por importantes revisões. Em 1983 foi constatado que, apesar da recente revisão, diversas agências do Governo Federal ainda não aplicavam as regras de concorrência e contratação pelo custo mais baixo. O diagnóstico era de que os processos de comparação de preços eram muito trabalhosos. A solução, adotada durante o governo Reagan, foi afrouxar as regras de concorrência, e permitir que as agências selecionassem de maneira mais livre seus parceiros privados (HALCHIN, 2007). Retomando o que foi discutido anteriormente, é em 1985, pouco tempo depois da revisão da circular, que o governo lança pela primeira vez uma concorrência para o LOGCAP, que seria aplicado a partir de 1988.

Apesar dos avanços na diretriz que estimula terceirizações e privatizações de funções governamentais, ainda restavam obstáculos aos interesses privados. Como as agências deveriam indicar quais eram os serviços fundamentalmente públicos, e consequentemente indicar quais funções poderiam ser terceirizadas, os grupos de funcionários do governo se organizaram para garantir que suas funções não fossem afetadas. Porém, uma nova revisão da Circular A-76, no início de 2001, determina que as agências deveriam disponibilizar publicamente os custos de todas as suas atividades. Esses custos poderiam ser questionados por interessados privados, que demandariam que uma concorrência fosse aberta para aquele setor (HALCHIN, 2007).

A partir do final da década de 1980, e com mais força a partir da revisão de 2001, o DdD foi o principal organizador de concorrências no âmbito da Circular A-76. A grande diminuição de seus funcionários e consequente crescimento da dependência de contratados terceirizados passou a gerar preocupação nos formuladores de políticas. Segundo Grasso, um relatório do congresso estadunidense de 2013 afirma que:

There is concern among policymakers that some A-76 activities may be considered inherently governmental and should only be performed by federal employees. DOD has relied on conducting A-76 competitions in an effort to achieve greater savings to finance defense operations and support costs. Since the end of the Cold War, DOD had substantially reduced the size of its force structure and sought to achieve additional cost savings through a greater reliance on public-private competitions through Circular A-76. (GRASSO, 2013, p. 3) 
Ao observar os gráficos apresentados na seção anterior, é possível perceber, de fato, a tendência de redução dos contingentes militares a partir do final da Guerra Fria. No entanto, em termos de gastos, uma ruptura importante ocorre entre os anos de 2000 e 2005. Embora os contingentes militares regulares se mantenham estáveis no período, os gastos militares explodem, num movimento de incessante crescimento ao longo da década. Entre o ano de 2000 e 2010, os gastos em defesa dos Estados Unidos aumentaram mais de 130\%.

Se a proporção de funcionários privados em relação às tropas oficiais se mantém entre as Guerras dos Balcãs e as Guerras no Afeganistão e Iraque, os números absolutos de militares, e por consequência, de civis envolvidos, de conflito a conflito, aumentam muito. Somando Iraque e Afeganistão, a quantidade de militares é quase dez vezes maior do que nos conflitos dos anos 1990. O que se verificou foi que em determinadas circunstâncias privatizar não significaria cortes de gastos, mas pelo contrário, um aumento descontrolado de contratos sem supervisão.

O período que compreende as ocupações no Afeganistão e no Iraque se tornou o grande balcão de negócios para as EMSP, que passaram a oferecer toda a sua gama de serviços de segurança. Nesses dois casos se cruzaram todas as funções para as quais as empresas haviam se especializado, com a adição de algumas novas atribuições. A DynCorp, por exemplo, seguiu operando seus CFTs e o contrato LOGCAP para quantidades cada vez maiores de pessoas e equipamentos; passou a disponibilizar seus serviços de instrução e treinamento para os projetos de RSS; forneceu guarda-costas e seguranças privados para autoridades do governo americano e para o presidente afegão Hamid Karzai; além de expandir seus serviços de linguística e tradução. ${ }^{8}$ A Dyncorp já era uma prestadora de todos os serviços mencionados antes dos atentados do 11/9 e do anúncio da Guerra ao Terror. Mas as dispendiosas operações acabaram tornando a Dyncorp uma das maiores beneficiárias dos contratos para esse período, e tornou a empresa uma excelente opção de investimento.

Além da ampla gama de serviços, as guerras proporcionaram também uma multiplicação da quantidade de EMSP prestando serviços no Iraque e no

\footnotetext{
3 A compilação de atividades e contratos ao longo da década de 2010 foi feita a partir de informações fornecidas no website da própria empresa: https://www.dyn-intl.com/
} 
Afeganistão. Se para os grandes contratos são mencionados sempre um número pequeno de grandes empresas capazes de concorrer para a prestação de serviços intensivos em mão de obra e capital, diversas empresas menores e anteriormente desconhecidas passam a fazer parte do panorama dos serviços militares privados. No entanto, apesar de uma multiplicação de pequenas empresas especializadas em alguns serviços, a dinâmica de concentração pareceu prevalecer no período. Dos estimados US\$138 bilhões em contratos provenientes da Guerra do Iraque, estima-se que US\$ 72 bilhões tenham ficado com as dez maiores empresas, ou mais de 52\% do total (SCHWARTZ, 2010).

Em março de 2003, no mesmo mês em que se iniciam as operações dos EUA no Iraque, a DynCorp e suas subsidiárias foram adquiridas pela Computer Sciences Corportaion (CSC) por aproximadamente US\$ 914 milhões (MERLE, 2004). A CSC é uma das maiores empresas de serviços de TI no mundo, e também uma das maiores fornecedoras de serviços para o governo nos EUA. Em 2002, a CSC era a oitava maior beneficiária de contratos com o governo federal dos Estados Unidos. Em 2003, ano da aquisição da DynCorp, a CSC se tornou a quinta empresa no ranking dos maiores contratos junto ao governo federal dos EUA. Neste ano, os contratos atingiram o valor de aproximadamente US\$3,3 bilhões, dos quais cerca de US\$1,2 bilhão provinham de contratos da DynCorp (FEDSPENDING, 2015).

A partir da aquisição pela CSC, em 2003, a DynCorp passou por um processo de desmembramento de sua ampla gama de serviços. Menos de dois anos depois da aquisição, a CSC decidiu se afastar de funções que não fossem associadas ao núcleo de suas atividades de TI. Parte desse movimento significou a venda dos setores da DynCorp que não fossem diretamente ligados ao setor de tecnologia, incluindo serviços de aviação e de segurança. Em dezembro de 2004, o fundo Veritas Capital Fund ${ }^{9}$ adquiriu partes da DynCorp que incluíam a DynCorp International, a DynMarine e alguns dos contratos da DynCorp Technical

\footnotetext{
A Veritas Capital Fundé um fundo de private equity norte-americano especializado em aquisição e controle de empresas que prestam serviços para governos, em especial para o governo federal dos Estados Unidos. De acordo com descrição própria do fundo, as empresas controladas pelo grupo se encaixam dentro de uma de suas oito áreas de especialidade, todas ligadas a funções públicas: "Aerospace \& Defense, Communications, Education, Energy, Government Services, Healthcare, National Security, and Technology” (VERITAS, 2020).
} 
Uma genealogia das empresas militares e de segurança privada: a trajetória da empresa

DynCorp frente à formação do "mercado da força" nos Estados Unidos

Tomaz Oliveira Paoliello

Services. A CSC manteve os direitos do uso do nome DynCorp, e em 2005 foi fundada a empresa DynCorp International, nome atual da empresa. A aquisição alcançou o valor aproximado de US\$ 850 milhões (MERLE, 2004). O montante envolvido nessa transação demonstra a importância do crescimento desse setor no período. A empresa que tinha sido originalmente adquirida por US\$ 914 milhões pela CSC, teve aproximadamente metade de seus ativos revendidos por quase o mesmo valor em menos de dois anos. O impacto principal desse enorme crescimento é o valor projetado que a companhia viria a adquirir com a escalada das operações no Afeganistão e no Iraque.

Quando adquirida pela Veritas, a Dyncorp International tinha aproximadamente 14.000 funcionários, e era estruturada em duas grandes divisões operacionais. Neste momento já é possível vislumbrar a gama de serviços que a DynCorp oferece até os dias atuais. A primeira divisão, Field Training Services (FTS), operava nos setores anteriormente associados às origens da empresa. É a face "empresa de apoio militar"10 da DynCorp. De acordo com relatório da Bloomberg:

FTS provides aviation services and engineering and logistical support, ranging from fleet maintenance to modifications and overhauls on weapons systems, aircraft and support equipment to the DoD. The division's Contract Field Teams (CFT) deploy personnel teams to customers to supplement a customer's workforce. FTS also provides domestic aviation services to owners and operators of large aircraft fleets, including Andrews Air Force Base, Fort Hood, and Fort Columbus in the U.S. (BLOOMBERG, 2004)

\footnotetext{
10 Para a descrição dos diferentes tipos de funções desempenhadas pelas EMSP, utilizamos a tipologia produzida por singer (2008). De acordo com o autor, as funções das empresas poderiam ser divididas em três tipos. O primeiro tipo, as "provedoras militares" (military provider firm), atuam no ambiente tático, nos combates em si. Os empregados dessa empresa estarão diretamente envolvidos em combate, seja como soldados de fato, seja como pilotos, como forças especiais ou como comandantes. Esse tipo de função talvez seja a mais parecida com o que costumava se classificar de mercenário, combatentes contratados atuando por um dos lados do conflito (SINGER, 2008, p. 92). O segundo tipo, as "consultoras militares" (military consultant firm), atuam no treinamento e aconselhamento das forças do cliente. Esse tipo de empresa não se envolve diretamente no combate, não enfrenta o adversário, ao contrário das chamadas "fornecedoras militares"; no entanto, estão intimamente ligadas à forma de atuação das forças de combate para a qual trabalham (SINGER, 2008, p. 95-97). O terceiro tipo são as "empresas de apoio militar" (military support firm), que agem na logística, transporte, inteligência, apoio técnico e suprimento. Esse tipo de empresa tem se mostrado cada vez mais comum com a reestruturação das forças armadas dos países ocidentais, principalmente no Reino Unido e nos Estados Unidos.
} 
Já a divisão denominada de International Technical Services (ITS), ficou responsável pelas tarefas associadas às empresas chamadas "provedoras militares" e "consultoras militares" (SINGER, 2008). Se a divisão de FTS está associada a contratos de mais de 50 anos, a divisão de ITS representava as novas e promissoras áreas de atuação da companhia.

DynCorp International's ITS division provides logistical and security services, including international law enforcement training, logistics, base operations and personal and physical security. In February 2004, the company was awarded the Civilian Police, or CIVPOL, contract by the DOS to deploy civilian police forces from over 50 countries to nations throughout the world to train and offer logistical support to local police and to assist in reconstruction and infrastructure building. (BLOOMBERG, 2004)

No momento em que é adquirida pela Veritas, a DynCorp, já desprovida do setor de TI, toma a forma que terá até os dias de hoje. As funções e especialidades da empresa, são, neste momento, concentradas em atividades relacionadas às funções militares.

A Veritas Capital Fund controlou a DynCorp International do final de 2004 até o início de 2010, período que pode ser considerado, até o momento, como o auge do mercado da força (VARDI, 2010). A estimativa é que no período que vai até 2010, as guerras no Afeganistão e no Iraque tenham consumido aproximadamente US\$100 bilhões em contratos com o governo. No primeiro trimestre de 2005, 37\% das receitas da DynCorp eram provenientes de contratos cumpridos para operações no Iraque e no Afeganistão (MARKETWATCH, 2005). A importância desse período para os negócios das EMSP pode também ser demonstrada pelos valores da transação envolvendo a DynCorp International. Robert McKeon, chefe do fundo Veritas, investiu pessoalmente US\$ 48 milhões na aquisição da DynCorp, em 2004. Depois de aproximadamente cinco anos, no início de 2010, ele vendeu sua parte no investimento por US\$320 milhões, quase sete vezes o valor investido.

Em 2006, a DynCorp realizou uma oferta pública inicial (IPO) na Bolsa de Valores de Nova York. Essa oferta de ações teve o valor de US\$ 325 milhões de dólares (DEALBOOK, 2006), e ocorreu pouco tempo depois da empresa vencer a concorrência para prestar serviços de treinamento policial e de erradicação de 
drogas no Iraque. Em maio de 2005, aproximadamente três meses antes do anúncio da IPO, o DdE anunciou que a DynCorp iria receber o contrato "aid in the eradication of illegal drug operations" para o Iraque, no valor de US\$ 54 milhões (MARKETWATCH, 2005). A aquisição da DynCorp International pelo grupo Veritas demonstra uma transformação nas tendências observadas anteriormente no que se refere às dinâmicas de associação do capital ao setor de EMSP.

Durante boa parte de sua história, a DynCorp foi uma empresa operada de maneira independente, que teve o setor de prestação de serviços militares como parte de uma lista de outros serviços fornecidos. A partir da compra pelo grupo Veritas, a situação se inverte, a empresa se especializa na prestação de serviços militares, que passam a dominar suas receitas. Adicionalmente, torna-se uma divisão de grandes grupos de capital, que passam a buscar o investimento em EMSP como perspectiva de diversificação de investimento, tendo em vista o enorme crescimento das receitas no setor. Notavelmente, os contratos de guerra passam a ser um elemento especulativo relevante, fazendo dos conflitos um importante balcão de negócios para as EMSP e os grupos de capital.

A DynCorp é novamente negociada em abril de 2010, adquirida pela Cerberus Capital Management, um novo fundo de private equity norteamericano. A empresa segue sendo, até hoje, subsidiária do Delta Tucker Holdings, Inc., uma das empresas subsidiárias do grupo Cerberus. A transação foi de aproximadamente US\$1,5 bilhão (DEALBOOK, 2010). Apesar da enorme valorização da DynCorp ao longo da década de 2000, o grupo Cerberus tem aproximadamente US\$20 bilhões em bens e investimentos sob seu controle em diversas áreas, entre elas a de EMSP. Isso significa que, apesar da grande relevância da DynCorp para o setor de serviços militares, ela representa apenas 7,5\% dos investimentos do grupo Cerberus, um dos maiores grupos de capital do mundo.

A nova negociação da empresa coincide com o início do governo Barack Obama (2009-2017), que utilizou a proposta de encerrar as ocupações no Afeganistão e no Iraque como um dos seus principais pontos de campanha. A retirada de tropas, que de fato passou a se acelerar a partir de 2009, significou igualmente uma retirada de contratados terceirizados. Se no Iraque a proporção 
entre contratados civis e militares regulares no período da invasão era de aproximadamente 1/1, essa proporção tendeu a aumentar no período da reconstrução.

É possível observar, no gráfico a seguir (Figura 4), que no ano de 2010, momento de uma retirada maciça de tropas, os números de terceirizados passam a superar notavelmente a quantidade de forças regulares, chegando a uma razão próxima de 1,5/1. O processo, que se enquadra no modelo de explicações político-instrumentalistas (KRUCK, 2013), leva a crer que o acesso a serviços militares terceirizados permite que o Estado faça uma redução no número de tropas sem que diminua na mesma proporção sua presença militar. Em outras palavras, a retirada de tropas combinada com a permanência de contratados privados permite que se anuncie uma retirada ainda mantendo uma presença relevante. É possível, portanto, que os custos políticos de uma guerra crescentemente impopular ${ }^{11}$ possam ter sido reduzidos através da terceirização.

Figura 4 - Tropa oficial americana X número de contratados privados (Departamento de Defesa - Iraque)

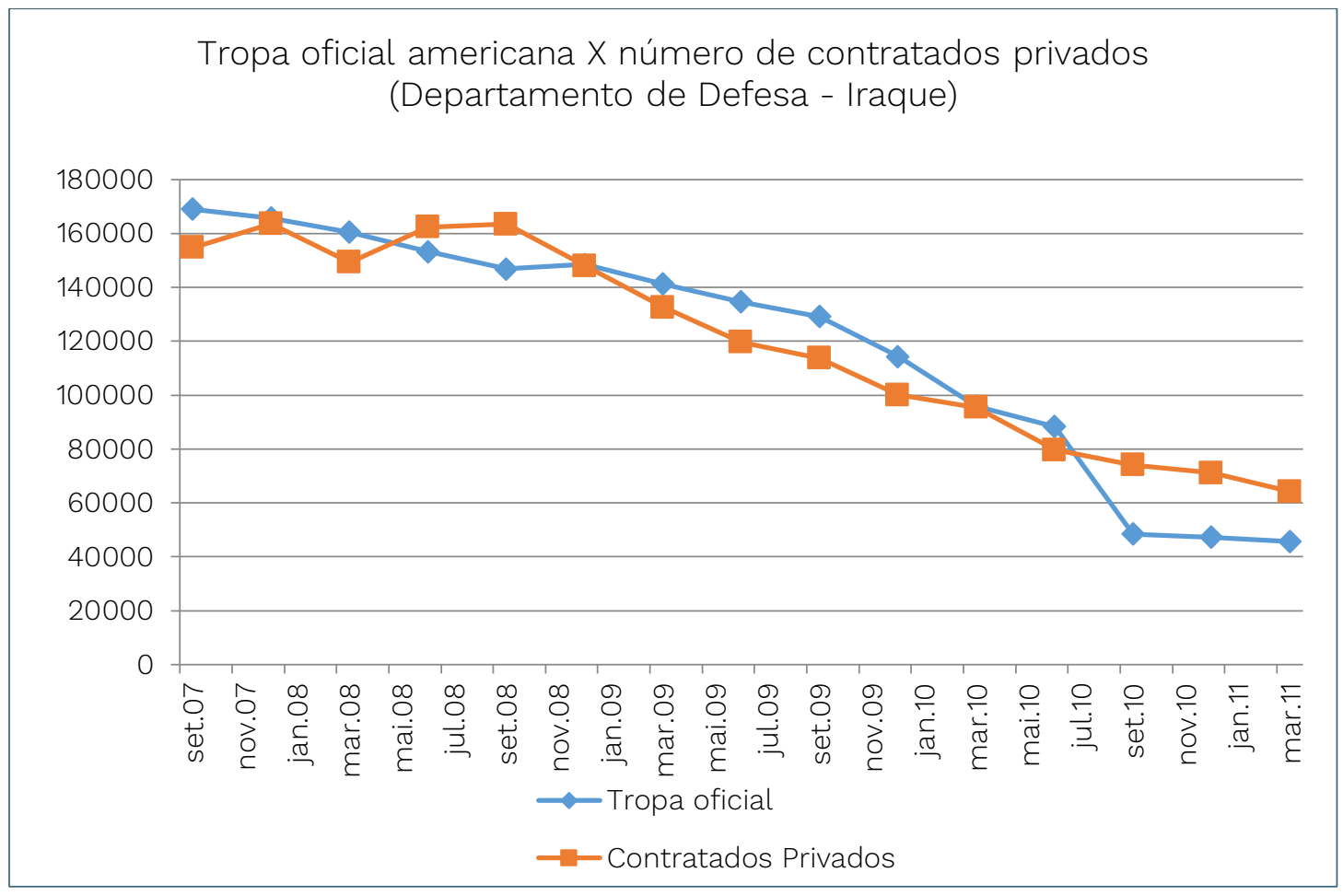

Fonte: (SCHWARTZ, SWAIN, 2011).

\footnotetext{
11 Em 2003, 79\% dos americanos eram favoráveis à guerra; em 2007, 65\% eram contra. (http://www.pollingreport.com/iraq.htm)
} 
É possível perceber que a formação das grandes empresas que dominam o atual panorama das EMSP passa por processos relativamente semelhantes. Seu crescimento está, em geral, associado à formação de demanda proveniente do governo, mais especificamente das Forças Armadas. Está, por outro lado, associado ao impulso proveniente de grandes grupos de capital, que procuram empresas militares para diversificar seus investimentos. Como já destacado, a escolha por investigar uma empresa especificamente deve trazer, em alguma dimensão, lições sobre o mercado em perspectiva geral. Se a DynCorp tem particularidades que a tornam um caso de estudo privilegiado, a empresa também segue tendências que a situam dentro de um processo estrutural amplo, e a equiparam às demais empresas militares.

Em 2015, a DynCorp é novamente reestruturada, e as funções da companhia são divididas em três setores. Esses setores representam as tendências atuais para o mercado das EMSP nos EUA. A DynAviation segue operando os contratos históricos de aviação da empresa. Essa divisão cuida dos serviços de mecânica e manutenção de aeronaves, operação de bases aéreas, e serviços de treinamento de pilotos. A DynLogistics é responsável pelos serviços de logística, operação e manutenção de quartéis e bases, e serviços de treinamento, inteligência e segurança. A DynLogistics opera, portanto, os contratos mais modernos de funções de apoio e logística da empresa. Por fim, a DynGlobal, desdobramento mais recente da empresa, busca novos clientes para além do Governo federal dos EUA, seu cliente majoritário. A formação dessa divisão indica também a grande dependência do mercado da força estadunidense de um único cliente, o governo dos EUA. Em 2015, o único cliente da divisão DynGlobal eram as forças militares australianas operando ao lado das tropas americanas no Afeganistão (DYNCORP, 2020).

\section{Conclusão}

Ao chegar ao ponto final da trajetória de fusões, aquisições, reorganizações e desmembramentos pelos quais passou a DynCorp, é possível perceber que a tendência de diversificação da empresa em diferentes setores da economia se manteve associada ao importante setor de prestação de serviços militares. 
Enquanto a empresa foi independente, o setor de prestação de serviços militares da companhia conviveu com outras áreas de investimento, que em geral se prefiguravam como os setores mais promissores nas relações público-privadas. Foi o caso do setor aeroespacial e nuclear nos anos 1950 e 1960; e o setor de computação e TI a partir do final dos anos 1980 e anos 1990. As demandas produzidas pelas novas economias e tecnologias foi acompanhada, ao longo da história dos EUA, por demandas produzidas pela série quase ininterrupta de operações militares lideradas pelo país.

A partir de 2003, data do início da Guerra do Iraque, quando a empresa é adquirida por grandes grupos de capital, a situação se mantém, embora de maneira inversa. O setor de serviços militares deixa de ser minoritário e se torna, ele próprio, um dos mais promissores setores de investimento para grupos de capital. Isso quer dizer que a DynCorp se torna, ela própria, um mecanismo de diversificação para investidores. Se a DynCorp passa a ser eminentemente uma empresa militar, ela estará associada a outros setores da economia através de seus controladores. Tanto em um caso quanto em outro, o setor da DynCorp que se identifica mais diretamente com uma EMSP nunca existiu dissociado de divisões ou de outras empresas do mesmo grupo que atuam em outras áreas da economia. O que parece variar é a importância que o setor de serviços militares teve dentro dos grupos dos quais a DynCorp fez parte, e essa variação tendeu à expansão, principalmente nos primeiros anos do século XXI.

A constatação de que o setor militar pode ser caracterizado também enquanto setor econômico, e via de regra conectado a outros mercados, indica uma agenda relevante de pesquisa para os conflitos contemporâneos. Subvertendo a afirmação de Clausewitz (2003, p. 27) de que "a guerra é uma simples continuação da política por outros meios", a trajetória da DynCorp desde sua fundação indica que a guerra pode ser considerada também uma extensão dos mercados por outros meios. Em outras palavras, a dimensão econômica dos conflitos pode e deve ser abordada não apenas relacionada aos fins da guerra, mas principalmente aos meios utilizados.

Os movimentos de oferta e demanda, as expansões e retrações das demandas militares nos EUA, indicam um processo longo de formação do 
chamado "mercado da força", e das empresas que operam nesse mercado. Se nossa realidade atual não pode ser explicada a partir de um mito fundador, como seria o final da Guerra Fria ou o anúncio da Guerra ao Terror, a genealogia desse tipo de empresa parece indicar um processo de mais longo prazo que seguirá se adaptando às circunstâncias políticas e econômicas dos conflitos contemporâneos.

\section{Referências}

AVANT, Deborah. The market for force: the consequences of privatizing security. Cambridge: University Press, 2005.

BLOOMBERG. Veritas Capital to acquire DynCorp International from Computer Sciences Corporation for $\$ 850$ million. Bloomberg. [S.l.], 12 Dec. 2004. Disponível em: http://www.businesswire.com/news/home/20041212005020/en/VeritasCapital-Acquire-DynCorp-International-Computer-Sciences. Acesso em: 23 mar. 2016.

CLAUSEWITZ, Carl von. Da guerra. São Paulo: Martins Fontes, 2003.

COLEMAN, David. U.S. Military Personnel 1954-2014. History in Pieces. [S.l.], 2015. Disponível em: http://historyinpieces.com/research/us-military-personnel-19542014. Acesso em: 23 abr. 2021.

DEAN, William Patrick. The ATL-98 carvair. Jefferson: McFarland \& Company Publishers, 2008.

DPAP (Defense Procurement and Aquisition Policy). Contingency contracting throughout U.S. history, 2015. Disponível em:

http://www.acq.osd.mil/dpap/pacc/cc/history.html. Acesso em: 23 mar. 2016.

DYNCORP. [S.l.], 2020. Disponível em: http://www.dyn-intl.com/. Acesso em: 23 abr. 2021.

EISENHOWER, Dwight. The farewell address. [S.L.], 1961. Disponível em: https://www.eisenhowerlibrary.gov/sites/default/files/research/onlinedocuments/farewell-address/reading-copy.pdf . Acesso em: 23 abr. 2021. 
FOUCAULT, Michel. Microfísica do poder. Rio de Janeiro: Edições Graal, 1979.

FUNDINGUNIVERSE. [S.L.], 2020. Disponivel em: http://www.fundinguniverse.com/company-histories/dyncorp-history/. Acesso em: 23 abr. 2021.

GRASSO, Valerie. Circular A-76 and the moratorium on DOD competitions: background and issues for congress. In: CONGRESSIONAL RESEARCH SERVICE, [S.l.], 2013. Disponível em: https://fas.org/sgp/crs/misc/R40854.pdf. Acesso em: 23 abr. 2021.

HALCHIN, Elaine. The federal activities inventory reform act and circular A-76. In: CONGRESSIONAL RESEARCH SERVICE. [S.l.], 2007.

HOLMQVIST, Caroline. Private security companies: the case for Regulation, SIPRI Policy Paper, Stockholm, n. 9, 2005.

HUSKEY, Kristine. The american way: private military contractors \& u.s. law after 9/11. In: PRIV-WAR Report. [S.l.], 01 Oct. 2010. Disponível em:

http://psm.du.edu/media/documents/reports_and_stats/think_tanks/privwar_na tional-report_huskey.pdf. Acesso em: 23 abr. 2021.

ISEMBERG, David. The unknown contractor. Huffington Post, New York, 29 May. 2010. Disponível em: http://www.huffingtonpost.com/david-isenberg/theunknown-contractor_b_517885.html. Acesso em: 23 abr. 2021.

JACQUETTE, Rogene. Contractor deaths in Iraq and Afghanistan outnumber service member deaths. New York Times, New York, 23 Sept. 2010. Disponível em: https://atwar.blogs.nytimes.com/2010/09/23/contractor-deaths-in-iraqand-afghanistan-outnumber-service-member-deaths/. Acesso em: 23 abr. 2021.

JLRB. Maintenance manpower. In: JOINT LOGISTICS REVIEW BOARD. Logistics support in the Vietnam era: monograph 13: maintenance. Washington, 18 Dec. 1970. p. 219-254.

KRUCK, Andreas. Theorising the use of private military and security companies: a synthetic perspective. Journal of International Relations and Development, London, n. 7, p. 112-141, 2013.

LOCK, Peter. Africa, military downsizing and the growth in the security industry. In: CILLIERS, Jakkie; MASON, Peggy (ed.). Profit and Plunder: the privatization of war and security in Africa. Pretoria: Institute for Security Studies, 1999. p. 11-36, 
postgraduate school, mba professional report. [S.l.], 2005. Disponível em: http://www.dtic.mil/cgi-bin/GetTRDoc?AD=ADA443449. Acesso em: 23 abr. 2021.

MARKETWATCH. DynCorp files \$450M IPO after merger. In: MARKETWATCH, [S.l.], 28 Sept. 2005. Disponível em:

http://www.marketwatch.com/story/dyncorp-files-450m-ipo. Acesso em: 23 abr. 2021.

MCFATE, Sean. The modern mercenary: private armies and what they mean to the world order. New York: Oxford University Press, 2014.

MERLE, Renae. Computer Sciences Sells DynCorp Units. The Washington Post, Washington, 14 Dec. 2004. Disponível em: http://www.washingtonpost.com/wpdyn/articles/A62259-2004Dec13.html. Acesso em: 23 abr. 2021.

O 'BRIEN, Kevin. Private military companies and african security 1990-1998. In: MUSAH, Abdel-Fatau; FAYEMI, J. 'Kayode. (eds.) Mercenaries: an african security dilemma. London: Pluto Press, 2000. p. 43-75.

OECD. The OECD DAC handbook on security system reform: supporting security and justice. [S.l.: s.n.]: 2007. Disponivel em: https://dx.doi.org/10.1787/9789264027862-en. Acesso em: 23 abr. 2021.

PIMENTEL, Cauê; PAOLIELLO, Tomaz. Empresas militares e de segurança privada. In: SAINT-PIERRE, Héctor Luis; VITELLI, Marina Gisela. (org.). Dicionário de segurança e defesa. São Paulo: Editora UNESP, 2018. p. 811-822.

SCHWARTZ, Moishe. Department of defense contractors in Iraq and Afghanistan: background and analysis. In: CONGRESSIONAL RESEARCH SERVICE. [S.l.], 2010.

SCHWARTZ, Moishe. SWAIN, Joyprada. Department of Defense Contractors in Afghanistan and Iraq: Background and Analysis. In: CONGRESSIONAL RESEARCH SERVICE. [S.l.], 2011. Disponível em:

https://fas.org/sgp/crs/natsec/R40764.pdf?utm_source=msn. Acesso em: 23 abr. 2021.

SEDRA, Mark. Introduction: The future of security sector reform. In: SEDRA, Mark (ed.). The future of security sector reform. [S.l.]: The Centre for International Governance Innovation, 2010a. p. 16-27.

SEDRA, Mark. Towards Second Generation Security Sector Reform. In: SEDRA, Mark (ed.). The future of security sector reform. [S.l.]: The Centre for International Governance Innovation, 2010b. p. 102-116. 
SINGER, Peter Warren. Corporate wariors: the rise of the privatized military industry. Ithaca: Cornell University Press, 2008.

SIPRI. SIPRI military expenditure database. [Stockholm]: Stockholm International Peace Research Intitute, 2020. Disponível em:

http://www.sipri.org/research/armaments/milex/milex_database. Acesso em: 23 abr. 2021.

TRAAS, Adrian. Engineers at war. Washington: Center for Military History, 2010.

UESSELER, Rolf. Servants of war: private military corporations and the profit of conflict. Trad. de Jefferson Chase. New York: Soft Skull Press, 2008.

VARDI, Nathan. dyncorp owner cashes out of wartime investment. Forbes, Jersey City, 12 Apr. 2010. Disponível em:

http://www.forbes.com/sites/streettalk/2010/04/12/dyncorp-owner-cashes-outof-wartime-investment/. Acesso em: 23 abr. 2021. 